\title{
AJARAN ETIKA DALAM UPANISAD BAGI REMAJA HINDU DI ERA GLOBAL
}

\author{
Putu Prysthia Dirna \\ Universitas Hindu Negeri I Gusti Bagus Sugriwa Denpasar \\ email : prysthiadirna@gmail.com
}

Diterima: 29 Maret 2021, Direvisi: 22 April 2021, Diterbitkan: 27 April 2021

\begin{abstract}
This paper aims to provide an understanding to the younger generation regarding the teachings of the Upanisad in instilling good behavior that can be applied in the family, school and community environment. The Upanisad is the essence of Vedic teachings which contains teachings on divinity, ritual, cosmos and ethics. Ethics is a teaching that teaches humans to have good character. The method used in this research is the literature study method. The results of the study indicate that the ethical teachings contained in the Upanisad can be used as a guide in living life in the global era. The ethical teachings contained in this upanisad are about satya, discipline, and self-control.
\end{abstract}

\section{Keywords : Upanisad, Ethics, Era Globalization}

\section{PENDAHULUAN}

Pada era global saat ini, kemajuan kehidupan manusia diwarnai oleh pesatnya perkembangan teknologi informasi dan komunikasi (TIK). Kehadiran dari teknologi informasi dan komunikasi (TIK) telah mengubah cara hidup masyarakat dunia dalam melaksanakan aktivitas sehari-hari. Kemajuan dalam penerapan TIK secara umum memiliki dampak positif maupun dampak negatif. Salah satu dampak negatif yang menyertai kemajuan TIK adalah menguatnya faham individualisme serta merosotnya moralitas khususnya di kalangan remaja. Menurut Soekanto (1982:8) penyimpangan-penyimpangan yang dilakukan oleh para remaja, merupakan perbuatan-perbuatan yang merugikan dirinya sendiri dan masyarakat. Misalnya suka bolos di sekolah, anak suka berdusta baik terhadap guru maupun pada orang tuanya, melakukan pemerkosaan, menipu, minuman keras, mencuri, berkelahi dengan teman sebayanya dan perbuatan lain yang bersifat merusak keindahan serta kelestarian lingkungan (Conduct Disonder). Perilaku menyimpang adalah tingkah laku yang melanggar atau bertentangan atau menyimpang dari aturan-aturan normati, dari pengertian-pengertian normative maupun dari harapan-harapan lingkungan sosial yang bersangkutan.

Sehubungan dengan hal tersebut, dewasa ini, fenomena tentang kenakalan remaja semakin hari semakin meningkat jumlah presentasinya, salah satunya yaitu banyaknya fasilitas- fasilitas yang ada di era globalisasi ini sebagian besar disalahgunakan oleh para penggunanya. Contoh, internet sekarang ini sering dijadikan arena untuk mencari situs-situs porno, handphone digunakan untuk menyimpan data-data yang tidak mendidik moral seseorang. Dalam tindakan pula, dikarenakan intensitas penggunaan gadget lebih tinggi maka banyak remaja yang lebih individualis, acuh dengan sekitar, kurangnya sopan santun terhadap sesama. Pengaruh globalisasi terhadap remaja ini begitu kuat. Dari uraian tersebut, permasalahan penting yang dihadapi oleh bangsa Indonesia sampai sekarang ini adalah pembentukan manusia Indonesia yang 
berkarakter. Salah satu hal yang dapat dilakukan untuk mengatasi hal tersebut yaitu dapat melalui pengajaran dalam Pendidikan Agama Hindu.

Pendidikan agama Hindu merupakan pendidikan yang mengarahkan tingkah laku umatnya untuk selalu berbuat dharma serta selalu bertaqwa kepada Ida Sang Hyang Widhi Wasa atau Tuhan Yang Maha Esa. Pendidikan Agama Hindu menekankan pada pendidikan susila atau etika budi pekerti manusia. Sesungguhnya susastra Hindu banyak sekali mengajarkan perilaku baik, luhur dan mulia untuk tercapainya ketentraman, keamanan, dan kedamaian dunia, seperti yang tertuang di dalam kitab suci Veda, tepatnya Upanisad.

Kitab Upanisad sendiri merupakan kitab bagian akhir atau kesimpulan dari kitab Veda. Mehta (2007: 45) mengungkapkan bahwa kitab Upanisad adalah risalah filosofis yang menguraikan pembelajaran Hindu, yang mana siswa diharapkan dapat memiliki pengetahuan rohani. Upanisad sendiri dapat diartikan sisya duduk di dekat kaki guru untuk mempelajari ajaran Upanisad. Esensi ajaran-ajaran yang tertuang di dalam Upanisad diantaranya yaitu ajaran filsafat, meditasi, konsep ketuhanan dan tidak luput pula mengenai ajaran etika.

Etika dalam terminology Hindu disebut "Susila: (bahasa Sanskerta) adalah perbuatan apa yang dianggap perbuatan baik dan perbuatan buruk. Etika sebagai bentuk pengendalian diri dalam hidup bersama, di mana aturan-aturan untuk bertingkah laku itu telah diatur dalam ajaran tata susila.Etika adalah suatu tingkah laku secara sadar yang dilaksanakan oleh manusia, untuk kebahagiaan serta keharmonisan hidup dan menyangkut tentang hak dan kewajiban moral (sradha), antar sesama manusia dengan alam serta dengan Ida Sang Hyang Widhi Wasa.

Pembelajaran agama Hindu yang tertuang di dalam Upanisad khususnya mengenai ajaran etika diharapkan dapat meningkatkan pengetahuan agama serta menanamkan perilaku yang baik bagi generasi muda dan dapat diaplikasikan dalam lingkungan keluarga, sekolah dan masyarakat.

\section{METODE}

Menurut Hasan (2002:80) metode kepustakaan adalah metode yang dilakukan dengan cara mendalami, mencermati, menelaah, dan mengidentifikasi pengetahuan yang ada dalam kepustakaan (sumber bacaan, buku-buku referensi atau hasil penelitian lain) untuk menunjang penelitian. Dalam penelitian ini penulis mengumpulkan data melalui sumber-sumber pustaka yang sudah dikaji dan berkaitan dengan permasalahan penelitian.

Metode studi kepustakaan dilakukan dengan membaca dan mempelajari hasil-hasil yang telah dipublikasikan menjadi buku-buku dengan cara membuat catatan, menyusun, dan menginformasikan dengan masalah dalam penelitian ini. Metode ini penulis gunakan untuk membantu mendapatkan informasi tentang hal-hal yang berkaitan dengan ajaran etika dalam upanisad bagi remaja hindu di era global.

\section{HASIL DAN PEMBAHASAN}

Kitab Upanisad secara harfiah dapat diterminologikan siswa atau sisya duduk dekat guru untuk mendengarkan ajaran suci (Radhakrishnan, 2008: 4). Makna 'duduk dekat di bawah guru' sampai saat ini oleh umat Hindu hanya dipandang sebagai metode belajar, padahal seperti dijelaskan Titib (1996:121), maksud duduk dekat di bawah guru adalah untuk menerima ajaran-ajaran yang bersifat rahasia. Jadi secara substantif, suasana percakapan itu harus mengandung kebutuhan untuk menjadikan proses belajar sebagai meta-dialog yang tidak bersifat fisik belaka, tetapi kondisi yang amat intim dan tidak berjarak antara acarya dengan sisya. Nilai bhakti akan menjadi jembatan utama yang menghubungkan hati sang acarya dengan sisyanya, sehingga seorang sisya diharapkan dapat mencerap lebih dalam wejangan suci yang diberikan acaryanya, lalu mendialogkannya secara kritis. Merujuk pada kodifikasi Veda, kitab upanisad merupakan kitab hasil dari pemikiran filosofis dalam universitas hutan (Aranyaka) yang kemunculannya diawali dari kitab Brahmana.Maka masing- 
masing kitab Brahmana memiliki puluhan kitab Upanisad yang merupakan bagian terpenting dari kitab Samhita Veda. Mehta (2007: 9) menguraikan bahwa tendensi filosofis dari kitab Samhita dikembangkan dalam kitab Upanisad, dan Upanisad merupakan bagian penting dari kitab-kitab Catur Veda Samhita, seperti disebutkan bahwa kitab-kitab ini diyakini dapat menghilangkan kebodohan dan kegelapan sehingga tumbuh karakter yang baik dalam diri manusia. Dua belas Upanisad yang penting menurut Sivananda (2003: 17) adalah (1) Isa, (2) Kena, (3) Katha, (4) Prasna, (5) Mundaka, (6)Mandukya, (7) Aitareya, (8) Taittiriya, (9) Chandogya, (10) Bahadaranya, (11) Kausitaki, dan (12) Svetavastara Upanisad. Kitab Upanisad merupakan intisari dari ajaran Veda yang membentuk pondasi dari ajaran Hindu, dan terkandung pemikiran filsafati berkenaan tentang Tuhan, ritual, kosmos dan juga etika.Merujuk pada uraian tersebut, penulis hanya lebih memfokuskan pada ajaran etika.

Etika merupakan satu komponen penting dalam ajaran agama Hindu.Etika Hindu adalah yang berkenaan dengan tata laku, tata krama atau sering dikenal dengan tata susila. Etika ini sangat penting untuk dijadikan acuan dalam bertingkah laku bagi generasi muda saat ini, sesungguhnya dasar dari ajaran etika Hindu terdapat dalam Upanisad, karena dalam Upanisad menekankan pentingnya hidup dengan etika. Adapun beberapa ajaran etika yang terkandung di dalam upanisad diantaranya yaitu, mengenaisatya (kebenaran) dantat twam asi(saling menghormati dan menghargai).

\subsection{Satya (Kebenaran)}

Menurut Kamus Jawa Kuna-Indonesia (Zoetmulder, 1995: 1057) satya berasal dari bahasa Sanskerta yang berarti benar; sungguh; setia; terpecaya; jujur (cinta kebenaran); patuh atau taat; baik. Kesetiaan dalam agama Hindu merupakan sebuah ajaran yang wajib kita amalkan. Kesetiaan dalam hidup merupakan hal yang sangat penting karena dengan kesetiaan kita bisa memperoleh sebuah kepercayaan dari orang lain. Kesetiaan dalam agama Hindu di kelompokkan menjadi lima jenis yang sering di sebut dengan Panca Satya. Panca Satya terdiri dari dua kata yaitu Panca dan Satya.Panca artinya lima dan Satya artinya setia, jujur dan tanggung jawab yang dalam sad acara disebutkan sebagai suatu kebenaran yang akan membawa manusia pada ketenangan. Adapun bagian dari Panca Satya itu yang terdiri dari (1) satya hredaya yaitu setia terhadap kebenaran dan kejujuran kata hati, berpendirian teguh, dan tidak terombang-ambing.Terkadang manusia sering mengabaikan bisikan hati yang paling dalam. Ingatlah kata hati adalah penuntun, jadi mulailah setia terhadap kata hati sendiri, niscaya penyesalan akan berkurang jika setiap orang menjalankan sesuatu sesuai dengan kata hatinya sendiri, (2) satya wacana yaitu setia, jujur dan benar dalam berkata-kata. Tidak mengucapkan kata-kata yang tidak sopan.Satya Wacana mengajaran kita untuk selalu berkata yang baik dan sopan kepada sesama. Saat ini banyak orang-orang yang berani mengucapkan kata-kata kasar, terutama remaja yang berani berkata kasar terhadap orang tuanya ataupun teman sebayanya.Orang tua adalah orang yang merawat kita sejak lahir, sudah sepatutnya kita menghormati mereka. Maka dari itu, diharapkan agar orang-orang saat ini lebih mengendalikan ucapan yang tidak sopan dan belajar berkata-kata yang baik, (3) satya semayayaitu setia, jujur, dan bertanggung jawab terhadap janji yang telah diucapkan. Satya Semaya mengajarkan kita untuk selalu menepati apa yang telah kita ucapkan, tetapi saat ini banyak sekali orang-orang yang melupakan apa yang telah ia ucapkan. Seperti di dalam pemerintahan banyak cerminan orang yang hanya bicara dan tidak menepati apa yang telah ia ucapkan. Maka dari itu mulai saat ini, belajarlah untuk setia dan bertanggung jawab terhadap apa yang telah diucapkan(4) satya mitra yaitu setia dan jujur kepada teman dalam segala hal. Teman adalah bagian penting dalam hidup.Sebagai mahluk sosial, manusia membutuhkan teman untuk berbagi segala suka dan duka, keluh kesah.Jadi setiap orang perlu setia terhadap temannya, karena manusia tidak bisa hidup sendiri dan selalu membutuhkan bantuan orang lain, terutama seorang teman, (5) satya laksana yaitu sikap setia dan jujur mengakui serta mempertanggungjawabkan kebenaran 
dari segala perbuatan yang telah dilakukan. Sebagai manusia, harus setia dan bertanggung jawab terhadap apa yang telah diperbuat. Berani berbuat, maka harus berani bertanggung jawab.

Kesetiaan sangatlah berarti dalam kehidupan. Dengan adanya rasa kesetiaan akan mampu mewujudkan kehidupan sosial yang sejahtera. Untuk itu perlu ditanamkan kesadaran untuk melaksanakan ajaran satya dengan sebaik-baiknya, sebagaimana dinyatakan dalam kitab Upanisad.

Satyam vada, dharmam cara

Svadhyayam ma pramadah

(Taittriya Upanisad I.11.1)

Terjemahan:

Berbicaralah selalu benar/tepat janji, berbuatlah kebajikan (dharma) tekunlah belajar Svadhyaya dan memuja-Nya dan jangan lalai.

\subsection{Tat Twam Asi (Saling Menghormati dan Menghargai)}

Tat Twam Asi adalah ajaran moral dari agama Hindu, yang mempunyai arti engkau adalah aku dan aku adalah engkau, yang mengandung asas: suka, duka, paras paros, salunglung sabayantaka, saling asih, saling asah, dan saling asuh. Filosofi yang terdapat dalam ajaran ini yaitu bagaimana kita bisa berempati, merasakan apa yang orang rasakan. Pentingnya solidaritas dalam kehidupan bermasyarakat sehingga terbentuk kehidupan masyarakat yang sejahtera (Hendra, 2013)

Di dalam kitab Chandogya Upanisad Tat Twam Asi disebutkan "Kaulah itu, Kaulah semua itu, dan Semua mahluk adalah engkau. Engkau awal mula dari jiwatman (roh) dan zat (prakrti) semua mahluk.Aku ini adalah mahluk yang berasal dari Mu.Oleh karena itu, jiwatmaku dan prakrti tunggal dengan jiwatman semua mahluk dan Dikau sebagai sumberku dan sumber segala mahluk.Oleh karena itu aku adalah Engkau dan aku adalah Brahman.Aham Brahma Asmi (Brhadaranyaka Upanisad 1.4.10). Dalam filsafat Hindu dijelaskan pula bahwa Tat Twam Asi adalah ajaran kesusilaan tanpa batas, yang identik dengan perikemanusiaan dalam Pancasila. Konsepsi sila perikemanusiaan dalam Pancasila, bila dicermati secara sungguh-sungguh merupakan realisasi dari ajaran Tat Twam Asi yang terdapat dalam kitab suci weda, seperti yang disebutkan sebagai berikut.

"Hyang amati-mati wang tan padosa, haywa anglarani sarwa prani, haywa kita tan masih ring wang nista"

Terjemahan:

Janganlah menyakiti mahluk hidup, janganlah tidak menaruh belas kasihan terhadap orang miskin atau orang yang ditimpa kemalangan

Tat Twam Asi mengajarkan kita untuk selalu mengasihi orang lain sebagaimana kita menyayangi diri kita sendiri. Inilah dasar utama untuk mewujudkan masyarakat yang damai dan makmur.Tat Twam Asi selalu mengamalkan cinta kasih, bhakti, dan rela beryadnya.

Cinta kasih sejati ditandai dengan cinta kepada kebenaran dan kebaikan, maka menjadi kewajiban setiap orang untuk selalu berbuat dharma. Bhakti adalah perwujudan hati nurani yang ditunjukkan kepada, (1) Ida Sang Hyang Widhi Wasa, seperti yang disebutkan di dalam kitab suci, brahman atman aikyam yang berarti atman dan brahman itu sesungguhnya tunggal. Hyang Widhi memancarkan sinarnya kepada semua mahluk yang menyebabkan adanya kehidupan di dunia ini.maka dari itu kita harus berbhakti kepada-Nya. (2) Orang tua, Orang tua adalah seseorang yang merawat kita dari kita bayi sampai dewasa, tanpa mengenal lelah ia selalu membesarkan dan menyayangi kita, maka dari itu setiap anak wajib dan harus berbakti 
kepada orang tuanya. (3) Guru, beliau mempunyai tugas yang mulia, mengajarkan kita dari tidak bisa menjadi bisa. Jasanya sangat besar terhadap kehidupan kita dalam hal mendidik.Oleh sebab itu, seorang siswa wajib bhakti dan hormat kepada gurunya. (4) Bangsa dan Negara, kita harus selalu siap dan sedia mengorbankan jiwa raga untuk memperjuangkan kemerdekaan bangsa yang mengandung arti bahwa setiap orang harus mendahulukan kepentingan umum daripada kepentingan pribadi. Dalam usaha untuk memerdekakan diri dari belenggu kegelapan, orang harus dapat mengalahkan musuh yang ada pada diri sendiri.

Ajaran Tat Twam Asi merupakan filsafat sosial, dan juga merupakan dasar dari tata susila Hindu di dalam usaha untuk mewujudkan perbaikan moral.Susila adalah tingkah laku yang baik dan mulia untuk membina hubungan yang selaras dan rukun diantara sesama mahluk hidup lainnya. Sebagai pedoman untuk membina hubungan yang selaras, maka kita patut mengetahui, memahami, dan mengamalkan ajaran tat twam asi dengan sungguh-sungguh.

Tata susila sering disebut juga dengan etika.Etika harus diterapkan sesuai dengan tujuannya, bila manusia memiliki wiweka yaitu kemampuan untuk membedakan yang baik dengan yang buruk.Selain itu, tata susila harus diperkuat pula dengan sastra-sastra agama.Diibaratkan dari suatu bangunan, jika landasan dari suatu bangunan tidak kokoh, maka bangunan itu akan mudah roboh dengan sendirinya. Demikian pula dengan tata susila ini.Ajaran agama yang yang dijadikan pedoman tata susila Hindu yaitu ajaran Tri Kaya Parisudha.Ajaran tersebut merupakan tiga kesusilaan yang penting sebagai bagian dari ajaran kebaikan. Oleh sebab itu, siapapun yang mengamalkan ajaran tersebut dengan kesungguhan hati, maka ia akan selau dalam keadaaan selamat dan bahagia. Namun kenyataannya saat ini, bila kita cermati sesungguhnya banyak sekali tanda-tanda kemerosotan moral di kalangan remaja. Hal ini dapat disebabkan oleh beberapa hal diantaranya, (1) kurang tertanamnya jiwa agama pada setiap individu dalam masyarakat, (2) pendidikan moral yang belum efektif terlaksana di lingkungan sekolah maupun di masyarakat, (3) situasi dan kondisi rumah tangga yang tidak baik, (4) kurang adanya bimbingan moral dari individu/lembaga bagi para remaja, dan (5) pesatnya efek dari globalisasi, dimana saat ini kemajuan IPTEK melahirkan berbagai macam media seperti tv, handphone, internet dan lain-lain. Banyaknya informasi yang bisa diakses dari media tersebut menyebabkan para remaja menyalahgunakan media tersebut.

Ajaran tat twam asi jika dilaksanakan secara sungguh-sungguh dan tulus hati dalam kehidupan sehari-sehari maka akan dapat membuat hidup ini menjadi rukun dan damai. Antara satu dengan yang lain dapat hidup saling menghormati, menghargai, dan menyayangi. Demikianlah ajaran tat twam asi yang patut kita pahami, dan implementasikan di dalam kehidupan.

\subsection{Pengendalian diri}

Pengendalian diri merupakan suatu kemampuan untuk tidak melakukan hal yang tidak patut dilakukan. Dengan pengendalian diri maka seseorang akan dapat hidup berdampingan secara harmonis yang tercermin dari etika atau perilaku sopan santun dalam pergaulan. Kerukunan dalam hidup akan semakin harmonis apabila dilandasai dengan toleransi terhadap perbedaan. Seseorang akan mudah bergaul dengan sesamanya apabila ia dapat menghargai dan tidak membeda-bedakan antara yang satu dengan yang lainnya.

Pengendalian diri juga merupakan salah satu kebutuhan remaja yang harus dipenuhi (Jahja, 2011). Menurut Arnett (dalam Gunarsa, 2004) menyatakan bahwa remaja membutuhkan pengendalian diri karena remaja pada umumnya berada pada masa badai dan tekanan. Remaja berada pada masa badai dan tekanan karena remaja telah memiliki keininginan bebas untuk menentukan nasib sendiri, jika terarah dengan baik maka ia akan menjadi seseorang yang memiliki rasa tanggung jawab, namun jika tidak maka ia bisa menjadi seseorang yang tidak memiliki masa depan yang baik. 
Di dalam agama Hindu sendiri, pengendalian diri menjadi hal yang sangat penting untuk mengantarkan manusia menuju kebajikan, kebahagiaan, dan akhirnya mendapatkan kelepasan ikatan duniawi.Hal yang menjadi penuntun dari pengendalian diri ini ialah pikiran. Dalam agama hindu pikiran merupakan raja dari semua indriya. Oleh karena itu pengendalian pikiran sangat penting dalam bertingkah laku (etika).Dalam Katha Upanisad disebutkan sebuah analogi yang menyebutkan bahwa kereta dan kuda sebagai badan dan indriya serta pengendaliannya.

Atmanah rathinam viddhi,

Uariram ratham eva tu,

Buddhim tu sarathim viddhi,

Manah pragraham eva ca.

(Katha Upanisad 1.3)

Terjemahannya:

Ketahuilah bahwa sang pribadi itu adalah Tuannya

Kereta, badan itu adalah kereta. Ketahuilah bahwa kebijaksanaan itu adalah kusirnya dan pikiran adalah tali kekangnya, (Sura, 1991: 36)

Indriyani haya athur visayams

Tesu gocaran, atmanendrrya

Mano yuktam, bhoktety athur mamisinah

(Katha Upanisad 1.4)

Terjemahan:

Indriya, mereka menyebutkan kuda. Sasaran indriya adalah jalan sang pribadi dan dihubungkan dengan badan. Indriya dan badan itulah yang menikmati. Demikian orang pandai menerangkannya

Kutipan mantra Katha Upanisad di atas menyebutkan bahwa pengendalian indriya itu yang diumpamakan sebagai kuda. Apabila indriya dapat dikendalikan maka ia dapat menjadi kuda yang baik dan mengantarkan penunggangnya ke tempat tujuan. Namun apabila sebaliknya, maka indriya itu diibaratkan kuda binal yang mengantarkan penunggangnya menuju kesengsaraan.Oleh sebab itu, jelaslah bahwa pengendalian terhadap indriya itu serta menguasai atas pikiran yang membawa manusia pada keselamatan dunia dan ahirnya. Dengan mengendalikan indriya, maka keinginan yang muncul dapat diarahkan pada hal yang berguna demi tercapaikan kebahagiaan lahir batin. Indriya itu sendiri merupakan penghantar manusia ke jalan surga dan neraka.

Dalam kitab Sarasamuscaya disebutkan sepuluh macam pengendalian diri terhadap pikiran, perkataan, dan perbuatan.Adapun sepuluh macam pengendalian diri tersebut yaitu tiga macam pengendalian pikiran, diantaranya (1) tidak menginginkan sesuatu yang tidak halal, (2) tidak berpikir buruk terhadap orang lain, (3) tidak ingkar terhadap kebenaran karma phala.Empat macam pengendalian perkataan, diantaranya (1) tidak berkata kasar, (2) tidak mencaci maki, (3) tidak memfitnah, (4) tidak berbohong atau ingkar janji. Tiga macam pengendalian perbuatan, diantaranya (2) tidak membunuh atau menyiksa mahluk lain, (2) tidak melakukan perbuatan mencuri, (3) tidak melakukan perzinahan.

Segala keinginan sebenarnya muncul dari indriya, maka dari itu indriya harus dikendalikan agar membawa manusia itu pada kebahagiaan.Mengendalikan pikiran bukan berarti membunuh indriya itu, tetapi kita jangan sampai diperbudak olehnya, melainkan harus sebaliknya manusialah yang harus menguasai dan mengontrol indriya tersebut. Tanpa keinginan dan tanpa indriya, manusia akan bisa hidup. Sang Hyang Widhi telah 
menganugrahkan keinginan dan juga indriya itu untuk kesempurnaan manusia itu sendiri.Dengan demikian manusia harus selalu mengontrol atau mengendalikan keinginan atau indriya-indriya kepada sesuatu yang baik agar memperoleh keselamatan dan kebahagiaan dalam hidup.

Remaja saat ini sendiri pula diharapkan dapat memahami segala ajaran yang diajarkan mengenai pengendalian diri dalam Katha Upanisad, segala yang diajarkan di dalam Katha Upanisad tersebut sangat penting untuk direalisasikan di dalam menjalani kehidupan seharihari. Kemampuan mengendalikan diri ini memiliki fungsi untuk mencegah agar remaja tidak masuk dalam arus perubahan, seperti dalam bidang kejahatan sebab pengendalian diri yang rendah akan mengakibatkan seseorang menjadi mudah terpengaruh oleh hal-hal yang tidak baik

\section{KESIMPULAN}

Ajaran etika yang tertuang di dalam upanisad dapat dijadikan sebagai pedoman bagi masyarakat dalam menghadapi tantangan di era global saat ini yang mana memberikan dampak yang bermacam-macam bagi kehidupan. Ajaran etika di dalam upanisad sendiri ada mengenai satya (kebenaran), tat twam asi (saling menghargai dan menghormati), dan juga pengendalian diri. Ajaran-ajaran tersebut hendaknya dapat dipahami, dicermati, dan juga diamalkan di dalam kehidupan sehari-hari guna menuntun masyarakat khususnya remaja untuk menjadi pribadi yang baik dan luhur serta dapat mencapai kehidupan yang harmonis, rukun, dan juga damai.

\section{DAFTAR PUSTAKA}

Gunarsa, D.S. 2004. Psikologi Praktis: Dari Anak Sampai Usia Lanjut. Jakarta: PT. BPK Gunung Mulia.

Hasan, M. Iqbal. 2002. Pokok-pokok Materi Metodologi Penelitian dan Aplikasinya. Jakarta:

Ghalia Indonesia

Hendra, Novayana. 2013. "My World Tat Twam Asi” dalam

http://worlddehendra.blogspot.co.id/2013/11/tat-twam-asi.html

Jahja, Y. 2011. Psikologi Perkembangan. Jakarta: Erlangga Kajeng, I Nyoman, Dkk. 1997.Sarasamuccaya. Surabaya: Paramitha

Mehta, Rohit. 2007. Menemukan Tuhan dalam Diri. Terjemahan Tjok Rai Sudharta. The Call Of Upanisad. 1970. Denpasar: Sarad

Radhakrisnan, Sarvepali. 2008. Upanisad-Upanisad Utama. Surabaya: Paramitha

Sivananda, Sri Swami. 2003. Intisari Ajaran Hindu. Surabaya: Paramitha

Soekanto, Soerjono. 1982. Sosiologi Suatu Pengantar. Jakarta : Rajawali

Sura. 1991. Agama Hindu Sebuah Pengantar. Denpasar: CV Kayumas Agung

Titib, I Made, 1996. Weda Sabda Suci Pedoman Praktis Kehidu-pan. Surabaya: Paramita.

Zoetmulder, P.J. 1995. Kamus Jawa Kuna - In 